\title{
Effect of bovine lactoferrin addition to milk in yogurt manufacturing
}

\author{
I. Franco, E. Castillo, M. D. Pérez, M. Calvo, and L. Sánchez ${ }^{1}$ \\ Tecnología de los Alimentos, Facultad de Veterinaria, Universidad de Zaragoza, Miguel Servet 177, 50013 Zaragoza, Spain
}

\begin{abstract}
The aim of this work was to study the effect of milk supplementation with lactoferrin of different iron saturation on the manufacturing and characteristics of yogurt. Bovine lactoferrin was added at concentrations of $0.5,1$, and $2 \mathrm{mg} / \mathrm{mL}$ in the holo (iron saturated) and apo (without iron) forms. Some physicochemical properties, such as $\mathrm{pH}$, concentration of lactic acid, and texture of supplemented yogurts, were determined throughout the shelf-life period storage $(28 \mathrm{~d})$ at $4^{\circ} \mathrm{C}$. We also evaluated the stability of lactoferrin in supplemented yogurt throughout the storage time. The supplementation of milk with bovine lactoferrin did not greatly affect the physical properties of the yogurt, though apo-lactoferrin slightly delayed the decrease of $\mathrm{pH}$. This could be attributed to the partial inhibition observed on the growth of Streptococcus thermophilus. The integrity and immunoreactive concentration of lactoferrin, determined by Western blotting and noncompetitive ELISA, respectively, remained constant throughout the shelf life of yogurt.
\end{abstract}

Key words: bovine lactoferrin, yogurt, lactic acid bacteria, functional product

\section{INTRODUCTION}

Lactoferrin is a truly multifunctional iron-binding glycoprotein with a molecular weight of $80 \mathrm{kDa}$ and is found mainly in milk. It is also present in other biological secretions, such as saliva and tears (Farnaud and Evans, 2005). Lactoferrin molecule consists of a single polypeptide chain protein organized in a bilobal structure, with the capacity to bind 1 iron atom in each of the 2 lobes. The protein with a high percentage of molecules saturated with iron is known as holo-lactoferrin and the protein with a very low content of iron bound is called apo-lactoferrin (Sánchez et al., 1992a; Baker and Baker, 2009).

Lactoferrin exhibits several biological activities, most of them associated with the host defense system, and is active against a broad spectrum of microbial species

Received December 17, 2009.

Accepted July 1, 2010.

${ }^{1}$ Corresponding author: lousanchez@unizar.es such as bacteria, fungi, protozoa, and virus (Orsi, 2004; Egashira et al., 2007; Jenssen and Hancock, 2009). Two main mechanisms can be considered the basis of lactoferrin antibacterial activity: its iron chelating capacity that impedes the use of iron by the microorganisms, and the binding to the bacterial membrane, changing its conformation and stability and, consequently, the viability of bacteria (Farnaud and Evans, 2005). Lactoferrin shows activity against viruses by interacting with the viral envelope proteins or by interfering with viral attachment to target cells (Jenssen and Hancock, 2009). Furthermore, synergy has been demonstrated between lactoferrin and other mucosal proteins such as lysozyme, having potential advantages for the protection of these surfaces (Ellison and Giehl, 1991).

Many studies have reported other important properties of lactoferrin, such as antiinflammatory activity (Hayashida et al., 2004; Wakabayashi et al., 2006; Hartog et al., 2007) and antitumoral activity (Damiens et al., 1998; Madureira et al., 2007; Tomita et al., 2009). Lactoferrin has also been reported to promote the growth and development of bifidobacteria, the beneficial bacteria of intestinal microflora that are very important for the well-being of the newborn (Liepke et al., 2002; Griffiths et al., 2003).

Lactoferrin from bovine milk has been used in the food industry for more than $20 \mathrm{yr}$ in some countries such as Japan. Lactoferrin is now a component of certain products in the category of functional foods (Shah, 2001). The recent worldwide production scale of bovine lactoferrin is assumed to be more than $60 \mathrm{t} / \mathrm{yr}$ (Tomita et al., 2009). Lactoferrin is added as a component of yogurt, milk, dietary supplements, and pet supplements, and is also used in cosmetic products and tablet coats for oral treatment of saliva-deficient patients (Takahashi et al., 2007; Rahman et al., 2008, Tomita et al., 2009). However, few published studies examine the effect of technological processes on lactoferrin when it is used as a functional ingredient in food (Dupont et al., 2006). In the case of supplementation of a fermented milk with lactoferrin, it would be necessary to know whether the manufacturing process affects the integrity of this protein and whether the final product characteristics would be affected by the addition of lactoferrin. The preservation of lactoferrin integrity is essential to 
produce a supplemented yogurt that could contribute to alleviate symptoms caused by some gastrointestinal problems.

The aim of the present work was to study the effect of supplementation of bovine milk with bovine apo- and holo-lactoferrin in the manufacturing of yogurt. This effect was evaluated by determining the physicochemical and textural characteristics of the supplemented yogurts and the growth of lactic acid bacteria (LAB). The stability of lactoferrin in supplemented yogurts was also studied during yogurt production and throughout the storage period.

\section{MATERIALS AND METHODS}

\section{Preparation of Lactoferrin with Different Iron Saturations}

Bovine lactoferrin $(\mathbf{L F b})$ with an iron saturation of around 26\% was supplied by Fina Research (Seneffe, Belgium). Iron-depleted lactoferrin (LFb-apo) was obtained according to the method of Mazurier and Spik (1980). Iron-saturated lactoferrin (LFb-holo) was prepared saturating a $50 \mathrm{mg} / \mathrm{mL} \mathrm{LFb}$ solution in physiologic saline solution (PSS) with ferric nitriloacetic acid as described by Conesa et al. (2008). The solution of lactoferrin obtained was stored at $-20^{\circ} \mathrm{C}$ until use. The percentage of iron saturation of LFbholo was estimated at about $98 \%$ by measurement of absorbance ratio between 280 and $465 \mathrm{~nm}$ (Mata et al., 1994), which was above 0.048 .

\section{Isolation of Antibovine Lactoferrin Antibodies and Conjugation with Peroxidase}

Purified bovine lactoferrin was used as immunogen to prepare antisera in rabbits according to Conesa et al. (2008). The specific anti-LFb antibodies were obtained by immunoadsorption using a column with LFb insolubilized in Sepharose-4B (5 mg of protein/ $\mathrm{mL}$ of gel; Sigma, St Louis, MO) as follows. A 15-mL volume of antiserum was applied to the column, with a flow rate of $0.1 \mathrm{~mL} / \mathrm{min}$. The gel was washed with $15 \mathrm{~m} M$ sodium phosphate, $150 \mathrm{mM} \mathrm{NaCl}$ solution ( $\mathrm{pH}$ 7.4) until an absorbance lower than 0.02 at $280 \mathrm{~nm}$ was obtained. The antibodies retained by the gel were then eluted in 2-mL fractions with $0.1 \mathrm{M} \mathrm{HCl}$-glycine, $0.5 \mathrm{M}$ $\mathrm{NaCl}$ solution ( $\mathrm{pH} 2.8$ ). These fractions were neutralized immediately with $0.5 M$ Tris solution ( $\mathrm{pH}$ 8.0) and then dialyzed in a cellulose dialysis bag of 10,000 molecular weight cut-off against $15 \mathrm{~m} M$ sodium phosphate, $150 \mathrm{~m} M \mathrm{NaCl}$ solution ( $\mathrm{pH} 7.4$ ) concentrated in a stirred ultrafiltration cell (Millipore, Billerica, MA) with a membrane of 10,000 molecular weight cut-off in a nitrogen atmosphere and frozen at $-20^{\circ} \mathrm{C}$ until use. The purified antilactoferrin antibodies were conjugated with peroxidase as described by Catty and Raykundalia (1989).

\section{Noncompetitive ELISA Assay}

A noncompetitive sandwich ELISA assay was developed to determine bovine lactoferrin following the method of de Luis et al. (2008) with slight modifications. The wells were coated with specific anti-LFb antibodies $(5 \mu \mathrm{g} / \mathrm{mL})$ in $15 \mathrm{mM} \mathrm{Na} \mathrm{CO}_{3}, 35 \mathrm{mM} \mathrm{HNaCO}_{3}$ solution (pH 9.6) overnight at $4^{\circ} \mathrm{C}$. The wells were then washed with $1.5 \mathrm{mM} \mathrm{KH}_{2} \mathrm{PO}_{4}, 8 \mathrm{~m} M \mathrm{Na}_{2} \mathrm{HPO}_{4}, 3 \mathrm{~m} M \mathrm{KCl}$, $0.1 \mathrm{M} \mathrm{NaCl}$ solution (PBS; pH 7.4) containing $0.05 \%$ Tween 20 and blocked with $3 \%$ ovalbumin in PBS for $2 \mathrm{~h}$ at room temperature. The wells were washed again and the samples and LFb standards (10, 50, 100, 250, 500,750 , and $1,000 \mathrm{ng} / \mathrm{mL}$ ) were added to wells and incubated for $1 \mathrm{~h}$. The plate was then washed 5 times and specific anti-LFb antibodies conjugated with peroxidase at a dilution of 1:200,000 were added to wells and incubated for $1 \mathrm{~h}$. The plate was washed again and the wells were coated with the peroxidase substrate 3,3',5,5'-tetramethylbenzidine (ZEU-Inmunotec, Zaragoza, Spain) for $0.5 \mathrm{~h}$ and $50 \mu \mathrm{L}$ of $2 \mathrm{M} \mathrm{H}_{2} \mathrm{SO}_{4}$ was added immediately afterward to stop the enzymatic reaction. Absorbance was measured at $450 \mathrm{~nm}$ using plate reader equipment (Multiskan MS, Labsystem, Helsinki, Finland). Apo- and holo-LFb in the samples were quantified by interpolation of absorbance values in the calibration curve obtained with the standards of apo- or holo-LFb.

\section{Yogurt Manufacturing with Bovine Milk Supplemented with LFb}

The yogurt was made in sterile vials with commercial pasteurized semi-skimmed bovine milk ( $1.5 \%$ fat) in a volume of $1.5,3$, or $5 \mathrm{~mL}$, depending on the purpose of the assay. Commercial milk was supplemented with either of the 2 forms of lactoferrin, LFb-holo and LFb-apo. These proteins were added to milk as a concentrated solution of $50 \mathrm{mg} / \mathrm{mL}$ in PSS to get a final concentration in milk of $0.5,1.0$, and $2.0 \mathrm{mg} / \mathrm{mL}$. At the same time as lactoferrin supplementation, milk was inoculated with $0.01 \%$ of commercial yogurt lactic acid culture consisting of Streptococcus thermophilus and Lactobacillus delbrueckii ssp. bulgaricus (Danisco, Sassenage, France). Although some procedures of yogurt manufacturing include some method of concentrating the milk proteins to a higher level, we used commercial liquid milk already subjected to a high-heat treatment to have the whey proteins denatured to avoid syneresis. 
Yogurt prepared with milk without lactoferrin supplementation was used as a control. The incubation was carried out at $42^{\circ} \mathrm{C}$ until the $\mathrm{pH}$ of the control reached a value of 4.4, which was around $6 \mathrm{~h}$, and the yogurts were immediately refrigerated at $4^{\circ} \mathrm{C}$. Control samples, consisting of milk with lactoferrin at the same concentrations but without lactic bacteria, were incubated simultaneously. These experiments were repeated 3 times in different periods of time, and several parameters were measured in yogurt as indicated below.

\section{Measurement of Yogurt Parameters}

Measurement of $\boldsymbol{p H}$. $\mathrm{pH}$ was measured continuously during milk transformation into yogurt in a model experiment replicated 3 times, using milk samples of $3 \mathrm{~mL}$ and measuring $\mathrm{pH}$ by introducing a probe connected on a data acquisition system Almemo 5590 4.3.0/V5 for Windows XP (Ahlborn Mess, Holzkirchen, Germany). $\mathrm{pH}$ values were also determined in yogurts throughout their shelf life on d $0,1,2,3,6$, and 28 using a conventional pHmeter, after calibration with standard buffers.

Measurement of Lactic Acid Content. Lactic acid content was measured using an enzymatic kit (Boehringer Mannheim, Darmstadt, Germany), which is based on the oxidation of L-lactic acid to pyruvate by the enzyme L-lactate dehydrogenase (Gutmann and Wahlehfeld, 1974). The results were obtained by spectrophotometric reading at $340 \mathrm{~nm}$. The determination of lactic acid was carried out in samples on $\mathrm{d} 3,8$, and 28 after the manufacturing of yogurt.

Texture Profile Analysis. For texture analysis yogurt samples were kept in 5 -mL plastic containers (4.7 $\mathrm{cm}$ height, $1.5 \mathrm{~cm}$ i.d.) at $4^{\circ} \mathrm{C}$ for $24 \mathrm{~h}$ until analyzed. The firmness of yogurt, expressed by the extrusion force in newtons, was measured using the TA-XT2i Texture analyzer (Stable Microsystems, Godalming, UK) as described by Tamime et al. (1991) equipped with a cylindrical Kobe probe $(10 \mathrm{~mm}$ diameter, $35 \mathrm{~mm}$ long). The probe penetrated the samples to a depth of $15 \mathrm{~mm}$ at a fixed test speed of $1.0 \mathrm{~mm} / \mathrm{s}$ and the force exerted on the probe was recorded. Firmness was evaluated at $4^{\circ} \mathrm{C}$ in triplicate samples immediately after removal from cold storage.

Measurement of Bovine Lactoferrin Concentration. The immunoreactive concentration of apoand holo-LFb in yogurt samples was measured by the sandwich ELISA assay described previously. A $20-\mu \mathrm{L}$ sample of stirred yogurt was diluted with $180 \mu \mathrm{L}$ of PBS and then by a dilution factor of 1:1,000 or 1:2,000. The measurements were done on $\mathrm{d} 0,1,2,3,6$, and 28 after the manufacturing of yogurt.
Electrophoresis in Polyacrylamide Gel (SDSPAGE) and Western Blotting. Gels of 7.5\% acrylamide were used to perform SDS-PAGE (GE Healthcare, Uppsala, Sweden). Samples (200 mg) were taken from yogurts and, after $\mathrm{pH}$ adjustment to 6.8 , were centrifuged for $10 \mathrm{~min}$ at $9,500 \times \mathrm{g}$. Later, $50 \mu \mathrm{L}$ of the resulting whey was diluted with $40 \mu \mathrm{L}$ of $10 \mathrm{~m} M$ Tris (pH 8.0) and $10 \mu \mathrm{L}$ of $10 \mathrm{~m} M$ EDTA, 25\% SDS containing $0.1 \%$ bromophenol and the mixture was boiled for 5 min. The electrophoresis was carried out in a Phast System (Pharmacia, Uppsala, Sweden) and the gel was stained with Coomassie blue $\mathrm{R}$.

The electrophoresis was done in duplicate, staining one of the gels and using the other to perform the Western blotting assay. Immediately after separation, proteins were transferred from the gel to a nitrocellulose membrane using a MilliBlot-SDE Transfer System (Millipore), following the instructions given by the manufacturer, using $1 \mathrm{~mA} / \mathrm{cm}^{2}$ gel for $30 \mathrm{~min}$. Immunodetection of transferred protein was as follows: membrane was saturated with $5 \%$ ovalbumin in $15 \mathrm{mM}$ sodium phosphate, $150 \mathrm{mM} \mathrm{NaCl}$ solution ( $\mathrm{pH}$ 7.4) for $30 \mathrm{~min}$. Later, the membrane was washed with the same buffer 3 times and incubated with rabbit anti-bovine lactoferrin antisera at a dilution of 1:100 in 3\% ovalbumin in the same phosphate for $1 \mathrm{~h}$. The membrane was then washed again and was incubated with antirabbit IgG goat antibodies conjugated with peroxidase (Sigma) at a dilution of 1:1,000 in phosphate buffer with $3 \%$ ovalbumin. Finally, the membrane was washed 5 times and a solution of 4-chloro-1-naphtol dissolved in methanol, PSS, and $\mathrm{H}_{2} \mathrm{O}_{2}$ was used as substrate. All the incubations of the Western blotting assay were done at $37^{\circ} \mathrm{C}$.

Enumeration of LAB and Statistical Analysis To determine the effect of bovine lactoferrin on the viability of yogurt cultures, $1 \mathrm{~mL}$ of yogurt was prepared as detailed before with milk supplemented with LFbapo and LFb-holo at concentrations of $0.5,1.0$, and 2.0 $\mathrm{mg} / \mathrm{mL}$. The yogurt samples for LAB enumeration were taken at $0,2,4$, and $6 \mathrm{~h}$ during the manufacturing of yogurt, and the $\mathrm{pH}$ of each sample was also measured. The LAB enumeration was also carried out in yogurts throughout storage time at $4^{\circ} \mathrm{C}$, taking samples on $\mathrm{d} 0$, $2,4,8,16,20,24$, and 28 . The samples were prepared by diluting $50 \mu \mathrm{L}$ of yogurt in a sterile vial containing $450 \mu \mathrm{L}$ of sterile peptone water $(1 \%)$ and were thoroughly mixed for 1 min using a Vortex (IKA, Staufen, Germany). To choose the appropriate dilution for the counting in agar plate, the $6 \times 6$ drop plate method was used (Chen et al., 2003). Finally, the dilutions used were of $10^{-1}$ to $10^{-2}$ for Lactobacillus delbrueckii ssp. bulgaricus and $10^{-5}$ for Streptococcus thermophilus. Se- 


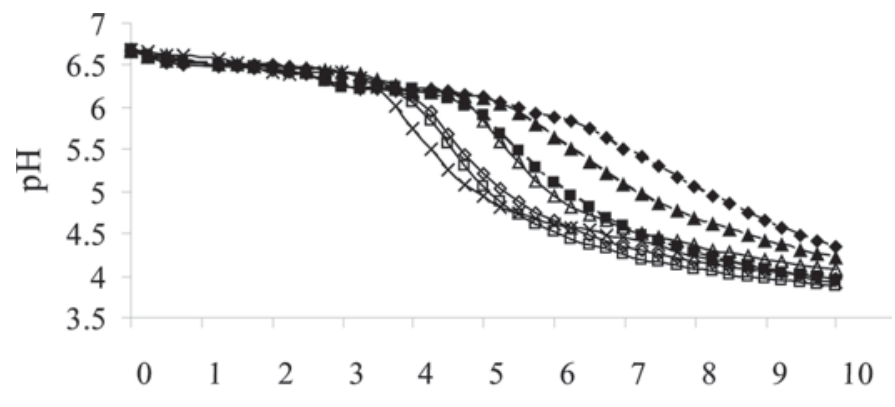

Time (h)

Figure 1. pH profile during yogurt production using bovine milk supplemented with different concentrations of bovine lactoferrin in the apo and holo forms. $=$ iron-depleted lactoferrin (LFb apo) $0.5 \mathrm{mg} /$ $\mathrm{mL} ; \boldsymbol{\Delta}=\mathrm{LFb}$ apo $1.0 \mathrm{mg} / \mathrm{mL} ;=\mathrm{LFb}$ apo $2.0 \mathrm{mg} / \mathrm{mL} ; \square=$ ironsaturated lactoferrin (LFb holo) $0.5 \mathrm{mg} / \mathrm{mL} ; \Delta=\mathrm{LFb}$ holo $1.0 \mathrm{mg} /$ $\mathrm{mL} ; \diamond=\mathrm{LFb}$ holo $2.0 \mathrm{mg} / \mathrm{mL} ; \times=$ control.

rial dilutions were done and plated in duplicate onto the media recommended by the International Dairy Federation (IDF, 1995) for the selective count of the 2 types of bacteria. These media were de Man, Rogosa, and Sharpe (pH 5.4; Biolife Italiana, Milan, Italy) and 0.5\% lactose M-17 (Merck, Darmstadt, Germany) for enumeration of Lactobacillus delbrueckii ssp. bulgaricus and Streptococcus thermophilus, respectively. The inoculated plates were incubated at $42^{\circ} \mathrm{C}$ for $48 \mathrm{~h}$ in anaerobic conditions for the growth of Lactobacillus delbrueckii ssp. bulgaricus by introducing the plates in anaerobic jars with gas pack AnaeroGen (Oxoid, Cambridge, UK). The plates with selective media for Streptococcus thermophilus were incubated in aerobic conditions at $42^{\circ} \mathrm{C}$ for $48 \mathrm{~h}$. The colonies were counted by a plate count technique.

The data obtained in texture analysis, determination of lactoferrin concentration, determination of lactic acid content, and enumeration of LAB were processed using ANOVA (SPSS 15 for Windows, SPSS Inc., Chicago, IL).

\section{RESULTS}

\section{Effect of Bovine Lactoferrin Addition on the Physicochemical Properties of Yogurt}

$p H$ of Yogurt. The evolution of $\mathrm{pH}$ in yogurts with the different supplementations was measured along time in an initial experiment (Figure 1). During the first $4 \mathrm{~h}$ of incubation a slight decrease in yogurt $\mathrm{pH}$ was found. Afterward, the $\mathrm{pH}$ of the control started to decrease more rapidly whereas there was a certain delay in $\mathrm{pH}$ decrease of the yogurts supplemented with lactoferrin, this decrease being slower in the yogurts supplemented with LFb-apo than in those supplemented with LFb- holo and especially slower in those supplemented with LFb-apo at 1 and $2 \mathrm{mg} / \mathrm{mL}$. From these results and for the following experiments, the incubation time for yogurt was stopped when the $\mathrm{pH}$ of the control yogurt reached 4.4, normally around $6 \mathrm{~h}$. The yogurts were kept at $4^{\circ} \mathrm{C}$ immediately afterward.

The variation in $\mathrm{pH}$ was measured throughout the whole yogurt shelf life (Figure 2). The "0 d" point represents the $\mathrm{pH}$ measurement taken immediately at the end of the incubation of yogurts and the following points represent the $\mathrm{pH}$ measurements taken on $\mathrm{d} 1,2$, 3,6 , and 28 of storage at $4^{\circ} \mathrm{C}$. At the end of the storage period $(28 \mathrm{~d}), \mathrm{pH}$ values were around 4.4 in the control yogurt and were lower, around 4.1, in the yogurts supplemented with LFb-holo at all concentrations. On the other hand, the $\mathrm{pH}$ values of the yogurts supplemented with LFb-apo ranged between 5.0 and 4.5 throughout the $28 \mathrm{~d}$ of storage, showing a decrease of $0.1 \mathrm{pH}$ unit on $\mathrm{d} 5$. The decrease of $\mathrm{pH}$ was directly related with the concentration of lactoferrin because higher lactoferrin concentration caused higher $\mathrm{pH}$ values compared with those of control and yogurts supplemented with LFb-holo. A decrease in $\mathrm{pH}$ of around $3 \%$ was observed across the 28-d storage period in the samples supplemented with LFb-apo, whereas a decrease of around $1 \%$ was observed for the same period in the samples supplemented with LFb-holo. These results indicate that the addition of the 2 forms of lactoferrin does not substantially affect $\mathrm{pH}$ values throughout the storage period of yogurt.

Lactic Acid Content. The variation in the lactic acid content throughout the shelf life of yogurts was also determined (Table 1). The lactic acid content of control yogurts increased in the first week of storage at

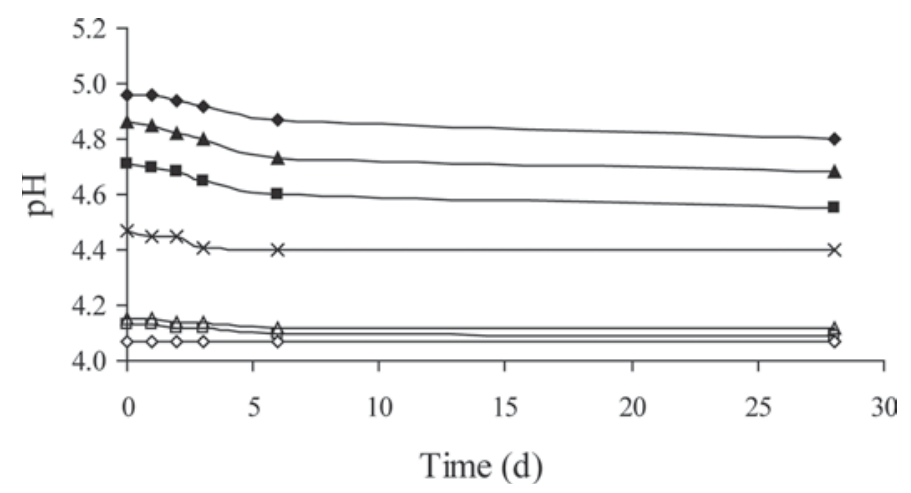

Figure 2. $\mathrm{pH}$ profile throughout the shelf life of yogurts supplemented with $\mathrm{LFb}$ in the apo and holo forms. Yogurts were maintained under incubation at $42^{\circ} \mathrm{C}$ for $6 \mathrm{~h}$ until $\mathrm{pH}$ of controls reached values of around 4.4. $=$ iron-depleted lactoferrin (LFb apo) $0.5 \mathrm{mg} / \mathrm{mL}$; $\boldsymbol{\Delta}$ $=\mathrm{LFb}$ apo $1.0 \mathrm{mg} / \mathrm{mL} ;=\mathrm{LFb}$ apo $2.0 \mathrm{mg} / \mathrm{mL} ; \square=$ iron-saturated lactoferrin (LFb holo) $0.5 \mathrm{mg} / \mathrm{mL} ; \Delta=\mathrm{LFb}$ holo $1.0 \mathrm{mg} / \mathrm{mL} ; \diamond=$ LFb holo $2.0 \mathrm{mg} / \mathrm{mL} ; \times=$ control. 
Table 1. Values of lactic acid concentration throughout the shelf life on d 3,8 , and 28 in yogurts supplemented with different concentrations of bovine lactoferrin ( $\mathrm{LFb}$ ) in the apo and holo forms and in a control yogurt without supplementation

\begin{tabular}{lccl}
\hline & \multicolumn{3}{c}{ Lactic acid concentration $(\mathrm{g} / 100 \mathrm{~g})$} \\
\cline { 2 - 4 } $\begin{array}{l}\text { Yogurt and lactoferrin } \\
\text { concentration }\end{array}$ & $\mathrm{d} 3$ & $\mathrm{~d} 8$ & $\mathrm{~d} 28$ \\
\hline LFb-apo $(\mathrm{mg} / \mathrm{mL})$ & 0.656 & 0.904 & 0.740 \\
0.5 & 0.689 & 0.789 & $0.693^{*}$ \\
1.0 & 0.683 & 0.661 & $0.648^{*}$ \\
2.0 & & & \\
LFb-holo $(\mathrm{mg} / \mathrm{mL})$ & 0.660 & 0.722 & 1.085 \\
0.5 & 0.666 & 0.735 & 1.007 \\
1.0 & 0.637 & 0.748 & $1.128^{*}$ \\
2.0 & 0.740 & 0.922 & 0.721 \\
Control &
\end{tabular}

*Significant differences from control $(P<0.05)$ by Scheffé's method of statistical analysis.

$4^{\circ} \mathrm{C}$ from around 0.68 to maximum values of $0.92 \mathrm{~g} / 100$ g. The lactic acid content in the yogurts supplemented with LFb-apo at concentrations of 0.5 and $1.0 \mathrm{mg} /$ $\mathrm{mL}$ increased during the first week of storage, reaching values of $0.90 \mathrm{~g} / 100 \mathrm{~g}$ and $0.79 \mathrm{~g} / 100 \mathrm{~g}$, respectively, on $\mathrm{d}$ 8. Lactic acid then decreased to 0.74 and 0.69 $\mathrm{g} / 100 \mathrm{~g}$ in yogurts with 0.5 and $1.0 \mathrm{mg} / \mathrm{mL}$ of $\mathrm{LFb}-$ apo, respectively. However, in yogurts supplemented with LFb-apo at a concentration of $2 \mathrm{mg} / \mathrm{mL}$, lactic acid levels remained constant throughout the whole shelf life. The values of lactic acid concentration in yogurts supplemented with bovine LFb-holo increased constantly throughout the shelf-life period, reaching values slightly higher than the control. These results are consistent with the $\mathrm{pH}$ profile observed for yogurts supplemented with LFb-holo, for which lower values were found compared with those of the control at the end of the storage time.

Texture. The textural characteristics of yogurt elaborated with milk supplemented with lactoferrin

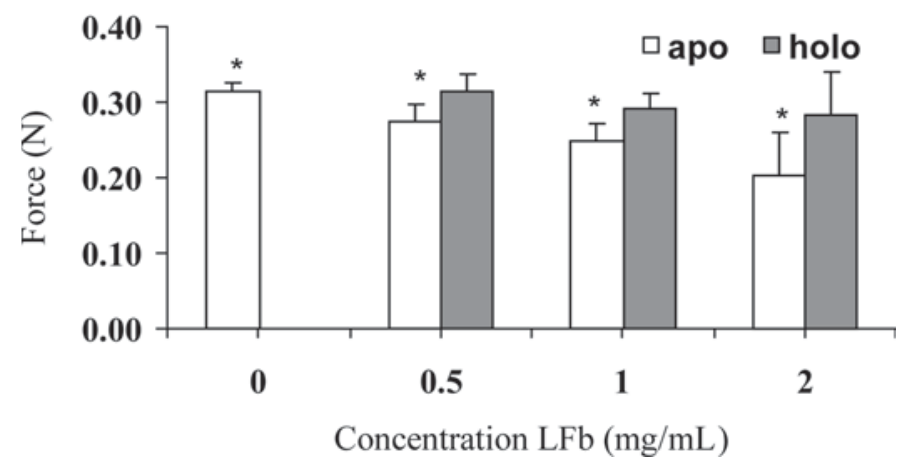

Figure 3. Effect of lactoferrin supplementation on the extrusion force in yogurts supplemented with bovine lactoferrin $(\mathrm{LFb})$ in the apo and holo forms at various concentrations. Asterisk indicates significant differences from control $(P<0.05)$. were determined by measuring the extrusion force with a compression test in intact yogurts. The sample was deformed until broken and the force was recorded as a function of deformation, this force being the extrusion force. The results obtained for all the supplemented yogurts are given in Figure 3. These measurements were done in triplicate in 3 independent experiments. The values of extrusion force for yogurts supplemented with LFb-holo did not show significant differences from that of the control, which presented a mean value of $0.315 \mathrm{~N}$. However, the extrusion force values for yogurts supplemented with lactoferrin in the apo form were significantly lower than the control, the lowest mean value being $0.204 \mathrm{~N}$ for yogurts with $2 \mathrm{mg} / \mathrm{mL}$ of LFb-apo.

\section{Effect of Lactoferrin on $L A B$}

The effect of lactoferrin addition on the growth of LAB was determined during the time of yogurt manufacturing (Table 2 and 3). The values of log colony-forming units per milliliter for Streptococcus thermophilus ranged from 7.91 to 8.77 (Table 2) at the end of yogurt incubation $(6 \mathrm{~h})$, and the counts found in the samples supplemented with LFb-apo at all concentrations were significantly lower than in those supplemented with LFb-holo. However, no differences were found at any time between the counts found in the yogurts supplemented with LFb-holo and in the controls.

Lactobacillus delbrueckii ssp. bulgaricus counts (Table 3) showed values of log colony-forming units per milliliter in the range from 5.34 to 5.98 at the end of yogurt incubation $(6 \mathrm{~h})$, and only the counts of samples supplemented with $2 \mathrm{mg} / \mathrm{mL}$ of LFb-apo were significantly lower than the control.

Table 2. Enumeration of Streptococcus thermophilus at 2, 4, and 6 $\mathrm{h}$ in yogurts supplemented with different concentrations of bovine lactoferrin $(\mathrm{LFb})$ in the apo and holo forms ${ }^{1}$

\begin{tabular}{lccc}
\hline & \multicolumn{4}{c}{ Colony count $(\log \mathrm{cfu} / \mathrm{mL})$} \\
\cline { 2 - 4 } $\begin{array}{l}\text { Yogurt and lactoferrin } \\
\text { concentration }\end{array}$ & $2 \mathrm{~h}$ & $4 \mathrm{~h}$ & $6 \mathrm{~h}$ \\
\hline LFb apo $(\mathrm{mg} / \mathrm{mL})$ & & & \\
0.5 & $8.30 \pm 0.24$ & $8.53 \pm 0.24$ & $8.05 \pm 0.25^{*}$ \\
1.0 & $8.25 \pm 0.28$ & $8.50 \pm 0.14$ & $7.91 \pm 0.08^{*}$ \\
2.0 & $8.24 \pm 0.06$ & $8.44 \pm 0.20$ & $8.22 \pm 0.19^{*}$ \\
LFb holo $(\mathrm{mg} / \mathrm{mL})$ & & & \\
0.5 & $8.36 \pm 0.14$ & $8.81 \pm 0.02$ & $8.77 \pm 0.08$ \\
1.0 & $8.55 \pm 0.03$ & $8.80 \pm 0.08$ & $8.73 \pm 0.06$ \\
2.0 & $8.39 \pm 0.07$ & $8.76 \pm 0.08$ & $8.77 \pm 0.14$ \\
Control & $8.40 \pm 0.19$ & $8.48 \pm 0.16$ & $8.59 \pm 0.13$ \\
\hline
\end{tabular}

*Significant differences from control $(P<0.05)$ by Dunnett's method of statistical analysis.

${ }^{1}$ Data are expressed as means of 4 values from 2 independent experiments. Initial colony counts: $6.391 \pm 0.21$. 


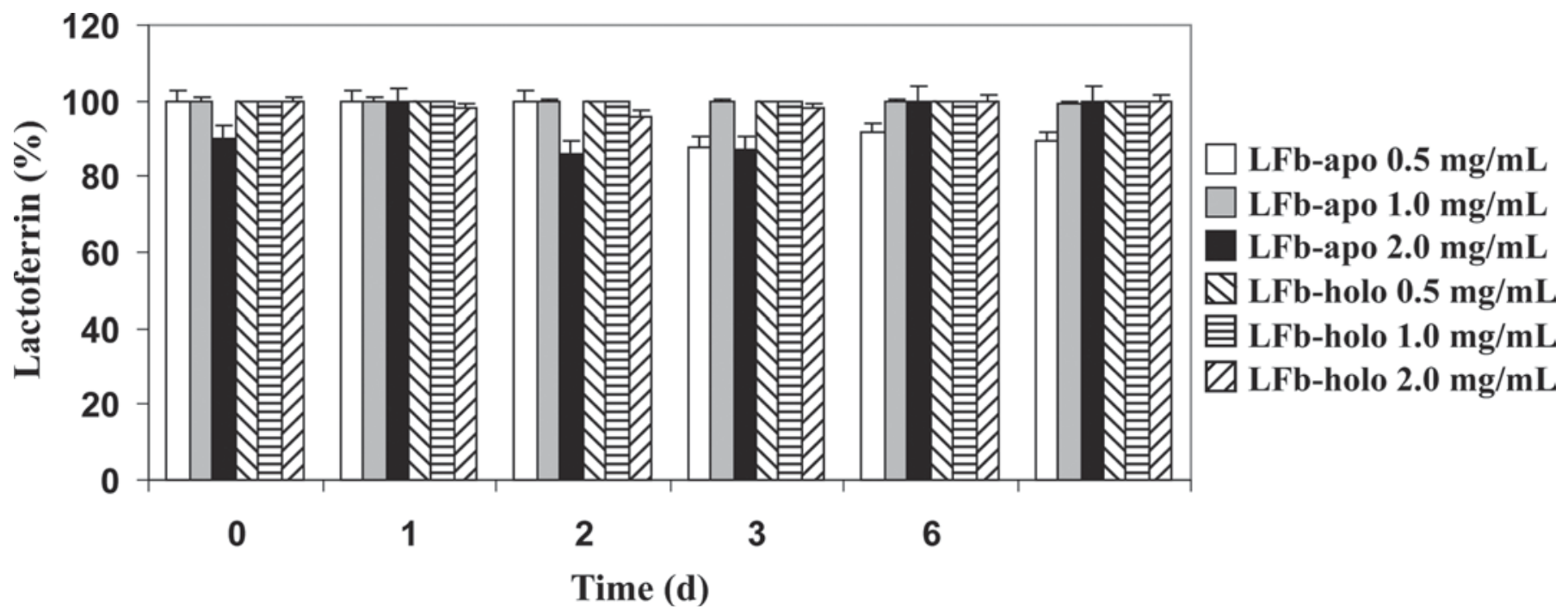

Figure 4. Concentration values of bovine lactoferrin in the yogurt samples throughout the storage time measured by a sandwich ELISA test. Values are expressed as percentage of the initial concentration. LFb apo = iron-depleted lactoferrin; LFb holo $=$ iron-saturated lactoferrin.

The 2 types of yogurt bacteria were enumerated at various times $(0,2,4,8,16,20,24$, and $28 \mathrm{~d})$ throughout the shelf life of yogurts supplemented with lactoferrin in the 2 forms and at different concentrations (data not shown). The bacterial counts were practically constant throughout the whole period, showing mean values of $\log$ colony-forming units per milliliter of $6.37 \pm 0.38$ for Lactobacillus delbrueckii ssp. bulgaricus and of $8.87 \pm$ 0.14 for Streptococcus thermophilus.

\section{Stability of Bovine Lactoferrin Throughout the Storage Time of Yogurt}

Lactoferrin stability in yogurt was determined by measuring its concentration by ELISA throughout the storage time. The antibodies obtained in our laboratory were specific for bovine lactoferrin and, after being conjugated with peroxidase, they were used to develop a sandwich ELISA. The data of absorbance obtained for standards in ELISA were adjusted to a polynomial equation, the correlation being above 0.98 and the detection limit being $36 \mathrm{ng} / \mathrm{mL}$. Commercial milk used for manufacturing yogurts was analyzed by ELISA, and lactoferrin was not detected. Figure 4 shows LFbapo and LFb-holo concentrations in the supplemented yogurts. In general, lactoferrin concentration remained constant throughout the storage period. However, some variations were observed in the concentration of bovine LFb-apo at some measurement points of the storage period.

Western blotting analysis was done to verify the integrity of lactoferrin throughout yogurt shelf life. This test was used to analyze yogurt samples supplemented with LFb-apo and LFb-holo at $0.5 \mathrm{mg} / \mathrm{mL}$ on $\mathrm{d} 6$ of storage, also including milk samples without lactic bacteria and supplemented with lactoferrin, which were used as control (Figure 5). All samples showed a single band corresponding to a molecular weight close to 80 $\mathrm{kDa}$, and no bands with lower molecular weights were observed.

\section{DISCUSSION}

The fermentation process of milk supplemented with different concentrations of lactoferrin at 2 levels of iron saturation was the first aspect considered in the present work. The results found for the $\mathrm{pH}$ profile along milk fermentation indicate that the addition of LFb-apo

Table 3. Enumeration of Lactobacillus delbrueckii ssp. bulgaricus at 2,4 and $6 \mathrm{~h}$ in yogurts supplemented with different concentrations of bovine lactoferrin $(\mathrm{LFb})$ in the apo and holo forms ${ }^{1}$

\begin{tabular}{lccc}
\hline & \multicolumn{4}{c}{ Colony count $(\log \mathrm{cfu} / \mathrm{mL})$} \\
\cline { 2 - 4 } $\begin{array}{l}\text { Yogurt and lactoferrin } \\
\text { concentration }\end{array}$ & $2 \mathrm{~h}$ & $4 \mathrm{~h}$ & $6 \mathrm{~h}$ \\
\hline LFb-apo $(\mathrm{mg} / \mathrm{mL})$ & & & \\
0.5 & $3.68 \pm 0.44$ & $4.90 \pm 0.53$ & $5.61 \pm 0.41$ \\
1.0 & $3.81 \pm 0.33$ & $5.03 \pm 0.50$ & $5.55 \pm 0.55$ \\
2.0 & $3.49 \pm 0.31$ & $4.62 \pm 0.37$ & $5.34 \pm 0.41^{*}$ \\
LFb-holo (mg/mL) & & & \\
0.5 & $3.71 \pm 0.46$ & $5.22 \pm 0.30$ & $5.96 \pm 0.12$ \\
1.0 & $3.80 \pm 0.31$ & $5.20 \pm 0.32$ & $5.98 \pm 0.08$ \\
2.0 & $3.79 \pm 0.41$ & $5.20 \pm 0.12$ & $5.78 \pm 0.05$ \\
Control & $3.76 \pm 0.07$ & $5.08 \pm 0.44$ & $5.97 \pm 0.04$ \\
\hline
\end{tabular}

*Significant differences from control $(P<0.05)$ by Dunnett's method of statistical analysis.

${ }^{1}$ Data are expressed as means of 4 values from 2 independent experiments. Initial colony counts: $3.245 \pm 0.07$. 
slows the $\mathrm{pH}$ decrease, suggesting a partial inhibitory effect on the growth and activity of LAB. In the case of the addition of LFb-apo at $0.5 \mathrm{mg} / \mathrm{mL}$, milk acidification was delayed and $\mathrm{pH}$ approached the value of the control yogurt around $7 \mathrm{~h}$ of incubation. This inhibitory effect increased with lactoferrin concentration, and in the yogurts supplemented with LFb-apo at 1 and 2 $\mathrm{mg} / \mathrm{mL} \mathrm{pH}$ reached that of the control at around $10 \mathrm{~h}$. In all the yogurts coagulation was observed, though in those with high level of lactoferrin the visual appearance was not as consistent as in the control yogurt. The fermentation of milk and its transformation into yogurt did not seem to be affected by the addition of LFbholo. Throughout the 28-d storage period of yogurt in refrigeration, the $\mathrm{pH}$ values of yogurts containing LFb-apo were higher than those of the control yogurts for the whole period. On the other hand, $\mathrm{pH}$ values of yogurts containing LFb-holo were lower than those of the control throughout the storage period. These results might indicate different responses of LAB to lactoferrin supplementation according to the type and concentration of lactoferrin.

Lactic acid and other organic acids are produced by the metabolic activity of LAB on milk lactose, causing $\mathrm{pH}$ decrease and, consequently, milk coagulation. In the present work, lactic acid content was found to be very similar in all types of yogurt in the first days of storage, increasing slightly along this period. However, at the end of the shelf life $(28 \mathrm{~d})$ yogurts supplemented with LFb-holo showed lactic acid levels approximately $50 \%$ higher than those of control and yogurts supplemented with LFb-apo. A similar evolution in lactic acid levels during the storage period of yogurt (up to $35 \mathrm{~d}$ ) has been reported by Dave and Shah (1997) for various LAB starters. However, they found lower lactic acid concentrations, in the range of 0.1 to $0.5 \mathrm{~g} / 100 \mathrm{~g}$ (at $35 \mathrm{~d}$ ), compared with our values of $0.9 \mathrm{~g} / 100 \mathrm{~g}$ (at 28 d), which were in agreement with those of other authors (Fernández-García and McGregor, 1994). These discrepancies might be attributed to the addition of different strains and different amount of LAB cultures to milk for fermentation into yogurt. The higher lactic acid levels found in yogurt supplemented with LFbholo indicate that this form of lactoferrin increases the metabolic activity of LAB whereas the apo form seems to exert a partial inhibition of their activity. The acidification and milk coagulation are directly related with lactic and other organic acids produced in the samples by LAB activity. These organisms maintain some activity, even at refrigerated temperatures, and produce small amounts of lactic acid by fermentation of residual lactose resulting in $\mathrm{pH}$ decrease.

Yogurt is manufactured using Streptococcus thermophilus and Lactobacillus delbrueckii ssp. bulgaricus as

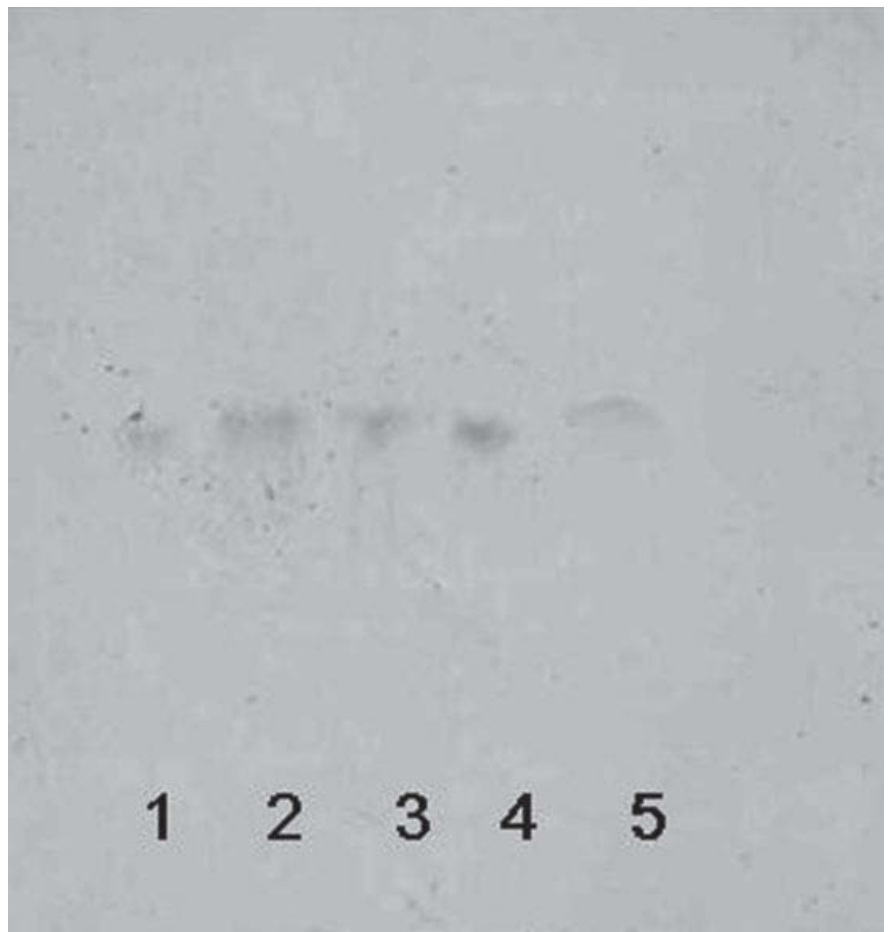

Figure 5. Transfer blotting of yogurt samples analyzed by $7.5 \%$ acrylamide gel SDS-PAGE. Lanes 1 and 2 correspond to milk added with bovine lactoferrin apo and holo, respectively, incubated at the same conditions as yogurts without lactic acid bacteria. Lanes 3 and 4 correspond to samples of yogurt elaborated with milk supplemented with bovine lactoferrin apo and holo respectively, and lane 5 corresponds to purified bovine lactoferrin in physiologic saline solution.

starter cultures. These bacteria are claimed to offer some health benefits; however, they are not natural inhabitants of the intestine (Shah, 2007). Furthermore, legislation specifies that there has to be a minimum number of $10^{6}$ colony-forming units of living LAB in yogurt (Birollo et al., 2000). As we have seen, the viable counts of Streptococcus thermophilus were around $10^{8}$ $\mathrm{cfu} / \mathrm{mL}$ in all types of yogurt during the fermentation time $(6 \mathrm{~h})$, whereas those of Lactobacillus delbrueckii ssp. bulgaricus showed an increase of $2 \log$ cycles at the end of fermentation compared with initial counts. In all cases, yogurts maintained the minimum counts of LAB required by legislation. The growth of Lactobacillus delbrueckii ssp. bulgaricus and Streptococcus thermophilus was not affected by supplementation of milk with LFb-holo, though their activity evidenced by lactic acid production along the storage period was enhanced by this form of lactoferrin. On the other hand, a certain inhibitory effect was observed at the end of the fermentation time $(6 \mathrm{~h})$ on the growth of Streptococcus thermophilus in yogurts supplemented with LFb-apo at all concentrations. The delay in the growth on Lactobacillus delbrueckii ssp. bulgaricus was observed only in the yogurt supplemented with the highest concentration 
of LFb-apo $(2 \mathrm{mg} / \mathrm{mL})$. These data were in accordance with lactic acid levels that were lower at the end of the storage period in yogurts supplemented with LFb-apo than in those supplemented with LFb-holo.

From our results, it can be suggested that yogurt LAB might use the iron bound to LFb-holo. This has been also found by Kim et al. (2004) studying the effect of lactoferrin on the growth of Lactobacillus acidophilus and finding that LFb-holo stimulates the growth of these bacteria. The authors suggested that this effect might be attributed to acquisition of iron bound to LFb-holo by Lactobacillus acidophilus, through interaction of lactoferrin with binding proteins on the bacterial membrane. Similar results were found by Miller-Catchpole et al. (1997) when they studied the growth of Bifidobacterium breve under conditions of iron deprivation and found that bacteria used the iron of the fully saturated lactoferrin. However, some controversy on this subject remains because Petschow et al. (1999) found that the ability of lactoferrin to stimulate the growth of some bifidobacteria is not dependent on the protein iron saturation level. On the other hand, in the work by Griffiths et al. (2003) the iron-saturated lactoferrin inhibited the growth of some lactobacilli and bifidobacteria species. The reasons for these differences are unknown despite the great deal of research performed on this topic.

Texture is one of the most important sensorial properties of set-type yogurt. In the present work, differences were found between the texture of yogurts supplemented with LFb-holo and those supplemented with LFb-apo. Yogurts supplemented with LFb-apo were not as firm as the control yogurts. The firmness of yogurt depends mainly on the activity of LAB; consequently, these results may be related with the certain inhibitory effect that LFb-apo exerted on LAB. The texture of yogurts with supplemented lactoferrin was not found to be very different from that of the control yogurt and was within the range of texture values previously reported in other studies (Hirano et al., 1998; Vercet et al., 2002).

The concentration of lactoferrin determined by ELISA remained practically constant in most of the samples except in yogurts supplemented with the apo form, in which the concentration was more variable along the storage period compared with the holo form. The thermal stability of lactoferrin depends on the environmental conditions, such as $\mathrm{pH}$, salts, and presence of other whey proteins, and also on the form of lactoferrin, the apo form being more heat-sensitive than the holo form (Sánchez et al., 1992b). The results of the present work have shown that the holo form does not seem to be affected by the temperature of incubation and by the acidic conditions of yogurt production, whereas the concentration of the apo form decreased up to $15 \%$ in some samples. Few investigations are available on the quantification of lactoferrin in supplemented milk products to corroborate label claims. However, Indyk and Filonzi (2005) determined lactoferrin in supplemented yogurt and other milk products using various methods, such as Sepharose and heparin liquid chromatography, ELISA, and surface plasmon resonance biosensor. They detected lactoferrin with 2 different immunochemical methods and with Sepharose chromatography and the results obtained were consistent. However, no protein was detected in yogurts when determining lactoferrin by the heparin method. This might indicate that the interaction between lactoferrin and heparin is affected by either the acidic conditions or the interaction of lactoferrin with other proteins in yogurt coagulum. These findings might explain the variations found in the concentration of LFb-apo in our work, which could be attributed to interaction of lactoferrin with other milk proteins, thus partially interfering in the reaction with specific antibodies.

Dupont et al. (2006) developed a test using specific monoclonal antibodies to determine bovine lactoferrin in cheese made with raw or pasteurized milk. They found that the pasteurization applied to milk $\left(72^{\circ} \mathrm{C}\right.$, $15 \mathrm{~s})$ did not decrease lactoferrin concentration; however, some factors involved in the cheesemaking process of soft cheese made with raw or pasteurized milk caused a decrease in the levels of immunoreactive lactoferrin.

In the present work, as revealed by Western blotting, lactoferrin seems to be intact in yogurt in agreement with the results obtained by Dupont et al. (2006) in cheese made with raw milk. We found a single band of $80 \mathrm{kDa}$, in correspondence with the single band observed in the analyses of Swiss-type semi-hard and soft cheeses made with raw milk in the study by Dupont et al. (2006). However, in the same types of cheese made with pasteurized milk the results showed a degradation product with a slight band at around $55 \mathrm{kDa}$. Our results indicate that lactoferrin structure does not seem to be altered by the activity of yogurt bacteria. Hence, this study demonstrated that yogurt is an excellent product for supplementation with lactoferrin, though it should be added after milk pasteurization because heat treatment could make lactoferrin more susceptible to proteolysis by LAB.

\section{CONCLUSIONS}

The addition of bovine lactoferrin to yogurt did not substantially affect the physicochemical properties of this fermented product. However, the growth of LAB is enhanced with the addition of LFb-holo, whereas the apo form exerts a certain inhibitory effect. On the other hand, the concentration and integrity of LFb are 
not substantially affected throughout the storage time of the product. From these results we can infer that yogurt is an adequate dairy product as a vehicle for a functional ingredient with interesting applications such as lactoferrin. At commercial level, the characteristics of the supplemented food must be similar to those of the nonsupplemented foods. In this way our results reveal that the addition of LFb-holo to the yogurt is more advantageous than addition of LFb-apo, although the small differences in texture of yogurt supplemented with LFb-apo could be compensated with a little increment in the nonfat DM of milk.

\section{ACKNOWLEDGMENTS}

This study was supported by a CICYT grant (AGL 2005-05494) from the Ministerio de Ciencia y Tecnología (Madrid, Spain) and by a research-fellow grant from Secretaría Nacional de Ciencia y Tecnología (SENACYT, Panamá, Panamá) of Gobierno de Panamá awarded to Indira Franco (from Gorgas Memorial Institute for Health Studies, Panamá, Panamá).

\section{REFERENCES}

Baker, E. N., and H. Baker. 2009. A structural framework for understanding the multifunctional character of lactoferrin. Biochimie 91:3-10.

Birollo, G. A., J. A. Reinhemer, and C. G. Vinderola. 2000. Viability of lactic acid microflora in different types of yogurt. Food Res. Int. 33:799-805.

Catty, D., and C. Raykundalia. 1989. ELISA and related enzymeimmuno-assay. Pages 97-154 in Antibodies: A Practical Approach. Vol 2. D. Catty, ed. IRL Press, Oxford, UK.

Chen, C. Y., G. Nace, and P. Irwin. 2003. A $6 \times 6$ plate method for simultaneous colony counting and MPN enumeration of Campylobacter jejuni, Listeria monocytogenes, and Escherichia coli. J. Microbiol. Methods 55:475-479.

Conesa, C., L. Sánchez, C. Rota, M. D. Pérez, M. Calvo, S. Farnaud, and R. Evans. 2008. Isolation of lactoferrin from milk of different species: Calorimetric and antimicrobial studies. Comp. Biochem. Physiol. B 150:131-139.

Damiens, E., J. Mazurier, I. El Yazidi, M. Masson, I. Duthille, G. Spik, and Y. Boilly-Marer. 1998. Effects of human lactoferrin on NK cell cytotoxicity against haematopoietic and epithelial tumour cells. Biochim. Biophys. Acta 1402:277-287.

Dave, R., and P. Shah. 1997. Viability of yogurt and probiotic bacteria in yogurts made from commercial starter cultures. Int. Dairy J. 7:31-41.

de Luis, R. L., L. Mata, G. Estopañán, M. Lavilla, L. Sánchez, and M. D. Pérez. 2008. Evaluation of indirect competitive and double antibody sandwich ELISA tests to determine $\beta$-lactoglobulin and ovomucoid in model processed foods. Food Agric. Immunol. 19:339-350.

Dupont, D., C. Arnould, O. Rolet-Repecaud, G. Duboz, F. Faurie, B. Martin, and E. Beauvier. 2006. Determination of bovine lactoferrin concentrations in cheese with specific monoclonal antibodies. Int. Dairy J. 16:1081-1087.

Egashira, M., T. Takayanagi, M. Moriuchi, and H. Moriuchi. 2007. Does daily intake of bovine lactoferrin-containing products ameliorate rotaviral gastroenteritis? Acta Paediatr. 96:1242-1244.

Ellison, R. T., and T. Giehl. 1991. Killing of gram-negative bacteria by lactoferrin and lysozyme. J. Clin. Invest. 88:1080-1091.
Farnaud, S., and R. Evans. 2005. Lactoferrin: The conductor of the immunological system? Pages 47-76 in New Research on Immunology. B. A. Veskler, ed. Nova Science Publishers, New York, NY.

Fernández-García, E., and J. U. McGregor. 1994. Determination of organic acids during the fermentation and cold storage of yogurt. J. Dairy Sci. 77:2934-2939.

Griffiths, E. A., L. Duffy, L. Schanbacher, D. Dryja, A. Leavens, R Neiswander, H. Qiao, D. Dirienzo, and P. Ogra. 2003. In vitro growth responses of bifidobacteria and enteropathogens to bovine and human lactoferrin. Dig. Dis. Sci. 48:1324-1332.

Gutmann, I., and A. W. Wahlehfeld. 1974. L(+) Lactate: Determination with lactate dehydrogenase and NAD. Pages 1464-1468 in Methods of Enzymatic Analysis. Vol 3, 2nd ed. H. U. Bergmeyer, ed. Academic Press Inc., New York, NY.

Hartog, A., E. Leenders, P. van der Kraan, and J. Garssen. 2007. Anti-inflammatory effects of orally ingested lactoferrin and glycine in different zymosan-induced inflammation models: Evidence for synergistic activity. Int. Immunopharmacol. 7:1784-1792.

Hayashida, K., T. Kaneko, T. Takeuchi, H. Shimizu, K. Ando, and E. Harada. 2004. Oral administration of lactoferrin inhibits inflammation and nociception in rat adjuvant-induced arthritis. J. Vet. Med. Sci. 66:149-154

Hirano, R., M. Hirano, M. Oooka, S. Dosako, I. Nakajima, and K. Igoshi. 1998. Lactoperoxidase effects on rheological properties of yogurt. J. Food Sci. 63:35-38.

Indyk, H., and L. Filonzi. 2005. Determination of lactoferrin in bovine milk, colostrum and infant formulas by optical biosensor analysis. Int. Dairy J. 15:429-438.

International Dairy Federation. 1995. Detection and enumeration of Lactobacillus acidophilus. IDF Bulletin No. 306. IDF, Brussels, Belgium.

Jenssen, H., and R. Hancock. 2009. Antimicrobial properties of lactoferrin. Biochimie 91:19-29.

Kim, W. S., M. Ohashi, T. Tanaka, H. Kumura, G. Kim, I. Kwon, J. Goh, and K. Shimazaki. 2004. Growth-promoting effects of lactoferrin on L. acidophilus and Bifidobacterium spp. Biometals $17: 279-283$

Liepke, C., K. Adermann, M. Raida, H. J. Mäegert, W. G. Forssmann, and H. D. Zucht. 2002. Human milk provides peptides highly stimulating the growth of bifidobacteria. Eur. J. Biochem. 269:712-718.

Madureira, A. R., C. I. Pereira, A. M. P. Gomes, M. E. Pintado, and F. X. Malcata. 2007. Bovine whey proteins. Overview on their main biological properties. Food Res. Int. 40:1197-1211.

Mata, L.. H. Castillo, L. Sánchez, P. Puyol, and M. Calvo. 1994. Effect of tripsin on bovine lactoferrin and interaction between the fragments under different conditions. J. Dairy Res. 61:427-432.

Mazurier, J., and G. Spik. 1980. Comparative study of the iron-binding properties of human transferrins: I. Complete and sequential iron saturation and desaturation of the lactotransferrin. Biochim. Biophys. Acta 629:399-408.

Miller-Catchpole, R., E. Kot, G. Haloftis, S. Furmanov, and A. Bezkorovainy. 1997. Lactoferrin can supply iron for the growth of Bifidobacterium breve. Nutr. Res. 17:205-213.

Orsi, N. 2004. The antimicrobial activity of lactoferrin: Current status and perspectives. Biometals 17:189-196.

Petschow, B. W., R. Talbott, and R. Batema. 1999. Ability of lactoferrin to promote the growth of Bifidobacterium spp. in vitro is independent of receptor binding capacity and iron saturation level. J. Med. Microbiol. 48:541-549.

Rahman, M., W. Sub Kim, H. Kumura, and K. Shimazaki. 2008. In vitro effects of bovine lactoferrin on autoaggregation ability and surface hydrophobicity of bifidobacteria. Anaerobe 14:73-77.

Sánchez, L., M. Calvo, and J. Brock. 1992a. Biological role of lactoferrin. Arch. Dis. Child. 67:657-661.

Sánchez, L., J. M. Peiró, H. Castillo, M. D. Pérez, J. M. Ena, and M. Calvo. 1992b. Kinetic parameters for denaturation of bovine milk lactoferrin. J. Food Sci. 57:873-879.

Shah, N. 2001. Functional foods, probiotics and prebiotics. Food Technol. 55:46-53. 
Shah, N. P. 2007. Functional cultures and health benefits. Int. Dairy J. $17: 1262-1277$.

Takahashi, Y., C. Takeda, I. Seto, G. Kawanob, and Y. Machida. 2007. Formulation and evaluation of lactoferrin bioadhesive tablets. Int. J. Pharm. 343:220-227.

Tamime, A. Y., M. Kaláb, and G. Davies. 1991. The effect of processing temperature on the microstructure and firmness of Labneh made from cow's milk by traditional method or by ultrafiltration. Food Struct. 10:345-352.
Tomita, M., H. Wakabayashi, K. Shin, K. Yamauchi, T. Yaeshima, and K. Iwatsuki. 2009. Twenty-five years of research on bovine lactoferrin applications. Biochimie 91:52-57.

Vercet, A., R. Oria, P. Marquina, S. Crelier, and P. Lopez-Buesa. 2002. Rheological properties of yogurt made with milk submitted to manothermosonication. J. Agric. Food Chem. 50:6165-6171.

Wakabayashi, H., K. Yamauchi, and M. Takase. 2006. Lactoferrin research, technology and applications. Int. Dairy J. 16:1241-1251. 